Article

\title{
Predictive Factors of Task Interdependence in the University Context
}

\author{
Santiago Mendo Lázaro *(D), Benito León Del Barco * , María-I Polo-Del-Río \\ and Irina Rasskin-Gutman $(\mathbb{D}$ \\ Department of Psychology, Faculty of Teacher Training College, University of Extremadura, 10071 Caceres, \\ Spain; mabelpdrio@unex.es (M.-I.P.-D.-R.); irasskin@unex.es (I.R.-G.) \\ * Correspondence: smendo@unex.es (S.M.L.); bleon@unex.es (B.L.D.B.)
}

Received: 22 October 2019; Accepted: 19 December 2019; Published: 21 December 2019

check for updates

\begin{abstract}
The aim of this research is to find out what type of task interdependence is generated in work teams in university contexts and to analyze the capacity to discriminate the type of task interdependence of some of the variables that are decisive for the team's success. The sample consisted of 808 teaching students from six Spanish universities. Self-report measures were taken, such as task interdependence, attitudes towards teamwork, team potency, and social team skills. The results show that the students who carry out the tasks in teams with high interdependence are minority. However, those who work with high interdependence, present more positive attitudes towards teamwork, greater team potency, and more social skills in receiving information and self-assertion. Likewise, high interdependence would be characterized by high scores in both the attitudes and team potency. However, attitude is the variable that better discriminates the type of task interdependence, allowing for an excellent level of discrimination of high interdependence.
\end{abstract}

Keywords: task interdependence; teamwork; attitudes; team potency; social skills

\section{Introduction}

Teamwork is a form of common interaction in different occupations and, therefore, an increasingly demanded competence that facilitates the adaptation of the worker to the current demands of the labor market [1]. Specifically, organizations are seeking professionals with attitudes for teamwork and cooperation [2], with social and collaborative skills becoming increasingly valued by employers [3].

As in the majority of business organizations, to conform a team and working towards a common task and objective, it is established as an essential aspect in the universities [4]. Since the establishment of the European Higher Education Area (EHEA), it is sought that university students must acquire a series of skills that prepare and train them for personal and professional life. Teamwork emerges as a transversal competence in the university field and is a requirement for the student [5].

In order for students to acquire this competence, the university teacher must make methodologies and training strategies based on team learning available to students so that they are able to build, organize, and manage their own learning process autonomously and cooperatively [6]. That is why teamwork under a cooperative structure is a key factor for the creation and active management of knowledge by students [2].

An important aspect of teamwork, built by the group of people themselves, is the interdependence that is created between their members as a result of the assumption of tasks to be performed and the objectives or goals to be achieved. The interdependence generated within the team is the essence of all teams $[7,8]$, and it indicates the degree to which their members interact with each other. It also indicates how the team members depend on each other to achieve their goals, to get involved in the task [9], or to achieve rewards [10]. 
Previous research distinguishes between different types of interdependence. Thompson [11] suggests that there are three forms of interdependence: (1) Pooled interdependence, which occurs when the work that one party does is not directly connected to the work that other parties do. (2) Sequential interdependence, which is characterized by the fact that tasks and activities have to be developed in a sequence that is present in the assembly lines. (3) Reciprocal interdependence, where each party or sector does something for the other, the outputs of both represent the inputs of the other. Therefore, it requires maximum coordination among them.

In the educational context, the cooperative learning theory [12] identifies positive interdependence as a mechanism for improving learning. In this sense, the elements of positive interdependence operationalize reciprocal interdependence [13], since the elements of positive interdependence (shared objectives, intertwined roles, shared resources, and joint rewards) conform to the definition of reciprocal interdependence [11]. That is, they are parameters designed to create situations where participants in a production system depend on each other for inputs and rewards.

Other studies distinguish between goals or targets interdependence [14,15], task interdependence [16], and reward interdependence [17]. Some argue for a unified complex interdependence that brings together these three aspects [18]. However, it is the task interdependence that forms the structural skeleton upon which the others are built $[19,20]$.

Task interdependence refers to the direction of the workflow, which makes team members interact with each other, to a greater or lesser degree, in order to successfully perform the task [21]. The awareness of team members that they are dependent on each other marks the beginning of a good job in performing or solving a particular task [22]. Without this interdependence, the team will not function properly and efficiently, and the success of the task will not be assured [23]. At the same time, when task interdependence is high, team members need greater coordination and group cohesion [24]. In short, it is determined by how tasks are divided and how team members share information, materials, or experiences [16].

The direct and positive relationship between interdependence and effectiveness of teamwork has been confirmed [25]. The research on the interdependence and effectiveness of teamwork in organizations exposes the modulating effect that the task interdependence has shown on many of the effects that different team processes have on organizational outcomes, that is, helping behaviors, confidence, communication, conflict, or flexibility [26].

Specifically, interdependence fosters greater knowledge and among team members and, at the same time, increases cooperation and cohesion among them [27], as well as ties of union based on the social interaction generated [25]. Task interdependence is also associated with high levels of creativity [28] and team performance [29].

In the same way that task interdependence has a positive influence on these variables, other different variables have also been observed that influence it. In this sense, motivation is an attitudinal variable that influences interdependence [30]. Satisfaction with the work done and conflict management leads to an increase in task interdependence [16,17]. Communication is another essential variable when it is necessary to join efforts and a high degree of interdependence between all the members of a team in order to perform a specific task $[4,19]$. When task interdependence is high, team members are required to interact with each other, thus, greater coordination and group cohesion is necessary [24] in which the social skills of team members are especially important [31].

On the other hand, there are a large number of variables at the group level that will determine the type of task interdependency given in a team. The belonging of people to a group generates the development of a social identity [32], a group identity and group norms [33], which orient their members towards the group as a whole, limiting unproductive behaviors and generating a greater number of cooperative behaviors. Likewise, collective intelligence, understood as the capacity of a group to collaborate and coordinate effectively, is very important for the performance of the group [34]. 


\section{This Study}

Just as task interdependence is a relevant variable in the functioning and effectiveness of teamwork in the organizational context, this type of interdependence is established as a facilitator of learning in the university context, being an important requirement in the performance of team tasks [35]. The interdependence generated in the team is a key factor in the organization of learning activities when working as a team [36]. A high degree of interdependence between them improves their levels of communication and planning for task coordination [37], being an influential variable throughout the teamwork process [38,39]. The way in which interdependence is perceived by students influences their response to the task. If it is perceived as unnecessary or irrelevant, it may result in students abandoning or performing the task individually. If it is clearly perceived, it will be considered important for the success of the task [4].

In addition to the task interdependence, there are many variables that can determine the effectiveness and success of learning teams. Most of them refer mainly to personal, academic, social, and affective elements [31]. Different studies give special importance to variables that, in a way, bring together these elements and are the result of the interactions and experiences of members within a team. They are directly related to the satisfaction and effectiveness of learning teams, such as team potency, academic and social attitudes towards teamwork, and social team skills. Team potency refers to the belief in team effectiveness [40] and is seen as a modulating variable between the relationship of interdependence and team effectiveness in organizational contexts [25]. Academic and social attitudes towards teamwork is understood as the individual will to continue working in a team [41]. A positive attitude to work in a team can only be developed if the competitive individualistic orientation is left aside [42]. This implies abandoning the belief that success depends only on one's own effort and requires trust in the ability of teammates [43]. Finally, social team skills [19], since the mastery of the social skills of team members is one of the basic mechanisms that order the existing interdependence among team members [44].

Despite the importance of task interdependence as a determining factor and/or related to emerging variables, resulting from the interactions and experiences of the members of the team who, in turn, mediate their success or failure, there is little research that addresses their study in the university context. The aim of this paper is to find out what type of task interdependence is usually generated in teamwork in university learning contexts and to study the similarities and differences in attitudes, team potency, and social team skills, depending on the type of interdependence perceived. The discriminant capacity of these variables will also be analyzed, on the type of task interdependence. We believe it is necessary to identify those variables that can discriminate the type of interdependence that students use when performing tasks or teamwork by establishing the score from which the interdependence is predicted.

\section{Materials and Methods}

\subsection{Participants}

The sample for this study is 808 teaching students (71\% female and $29 \%$ male), with an average age of 21.23 years $(\mathrm{ST}=4.98)$. The selection process of the participants was carried out by means of a cluster sampling in which six Spanish public universities were randomly selected. $42.3 \%$ of the participants are enrolled in the first grade, $29.7 \%$ in the second grade, and $28 \%$ in the third grade of the following Undergraduate Studies: Infant Education, Primary Education.

\subsection{Instruments and Variables}

2.2.1. Cuestionario de Actitudes Hacia el Trabajo en Equipos de Aprendizaje (CACTE) [Questionnaire on Attitudes Toward Learning Teams]

The CACTE questionnaire [43] is made up of 12 items that are answered using a 5-point Likert-type scale rating their degree of agreement from 1 (Totally disagree) to 5 (Totally agree). Two factors are 
involved: Factor 1: "Academic attitudes" (six items), which includes the assessment of the academic consequences of teamwork, (e.g., "My grades improve when working in a team"). Factor 2: "Social and affective attitudes" (six items), includes the assessment of interactions with other colleagues during teamwork, (e.g., "I feel useful and valued by my team mates"). The alpha indexes $(\alpha=0.90)$ and composite reliability $(\mathrm{CR}=0.92)$ show that the CACTE presents good global reliability and average variance extracted $(\mathrm{AVE})=0.52)$, Factor $1(\alpha=0.88, \mathrm{CR}=0.85, \mathrm{AVE}=0.51)$; Factor $2(\alpha=0.84, \mathrm{CR}=0.84$, AVE $=0.50)$.

\subsubsection{Cuestionario de Potencia de Equipos de Aprendizaje (CPEA) [Learning Team} Potency Questionnaire]

The CPEA questionnaire [40] is made up of eight Likert-type items with 10 response options ranging from 1 (Totally disagree) to 10 (Totally agree). The CPEA has two factors: the first, Confidence (four items), assesses students' expectations about their own team's efficacy. The second, Performance (four items), assesses students' perception of their team's capacity to successfully perform a series of academic tasks. Some items are: F1 "It is easy for my team to carry out any activity proposed in the different subjects"; F2: "The teamwork carried out by my team is of a very high quality". The $\alpha=0.87$ and the $\mathrm{CR}=0.85$ indicate that the CPEA presents good global reliability and AVE $=0.55$, Factor 1 $(\alpha=0.84, \mathrm{CR}=0.84, \mathrm{AVE}=0.54)$, Factor $2(\alpha=0.71, \mathrm{CR}=0.80, \mathrm{AVE}=0.53)$.

2.2.3. Cuestionario de Habilidades Sociales de Equipos de Aprendizaje (CHSEA) [Questionnaire of Social Skills Learning Teams]

The CHSEA questionnaire [19] is made up of 15 items that are answered using a 5-point Likert scale (from $1=$ "Totally disagree" to $5=$ "Totally agree"). The CHSEA aims to assess three factors or subscales of the social skills needed for team learning: (1) Self-assertion skills (I-messages, asking for changes in behavior, receiving criticism, stopping interaction), (2) Receiving information skills (actively listening, empathizing, summarizing, asking for help, asking questions), and (3) Imparting information skills (motivating, imparting information, convincing others, explaining oneself, giving help). The $\alpha=0.86$ and the $\mathrm{CR}=0.85$, indicate a good global reliability of the CHSEA, with an AVE $=0.59$, Factor $1(\alpha=0.75$, $\mathrm{CR}=0.77, \mathrm{AVE}=0.55)$, Factor $2(\alpha=0.83, \mathrm{CR}=0.80, \mathrm{AVE}=0.53)$. Factor $3(\alpha=0.81, \mathrm{CR}=0.80$, $\mathrm{AVE}=0.54)$.

\subsubsection{Task Interdependence}

This was assessed through the inclusion of three statements in the online questionnaire in which participants had to select the option closest to their overall experience in order to work in a team/group to accomplish tasks or university assignments. The three statements correspond to three types of interdependence based on previous proposals [11,21] modified for the context of this research, in order to refer to the three most common ways of dealing with the distribution of task when students work in teams:

(1) Low Interdependence: Each group member performs similar tasks independently; the final result of the group is due to the sum of the individual results.

(2) Medium interdependence: Each group member performs different tasks; one needs the result of the other to be able to complete his part of the work; the final result of the group is due to the contribution of each of the parties.

(3) High Interdependence: All group members cooperate simultaneously in the completion of tasks; the final result of the group depends on team member's reflection and cooperation.

\subsection{Procedure}

We contacted faculty members at the selected universities in the study, who facilitated the access to participants $(n=700)$ during the 2016/2017 academic year. The CACTE, the CPEA, and the CHSEA 
questionnaires were administered online through the Google Forms application (Google Drive tool). The completion of the questionnaires was anonymous, guaranteeing the confidentiality of the data obtained and their exclusive use for research purposes. Regarding the informed consent of participants, we follow the ethical guidelines of the American Psychological.

\subsection{Data Analysis}

The statistical package SPSS (version 21) was used for the analysis of the data collected. The reliability of the instruments used is calculated using Cronbach's Alpha, the Composite Reliability coefficients, and the Average Variance Extracted. Descriptive analyses were performed. Previous to contrast the assumptions of normality and homoscedasticity, multivariate analyses (MANOVA), discriminant, and receiver operating characteristic (ROC) curve were carried out.

\section{Results}

First, the distribution of students is presented according to the type of Interdependency (Low/Medium/High). In this sense, $14.5 \%$ of the students affirm that when they carry out tasks or team works, the final result is due to the sum of the individual results (Low Interdependence), $44.5 \%$ that is the product of the contribution of different parts that complete the work (Medium Interdependence), and $41 \%$ that depends on the reflection in group and the cooperation of all the members (High Interdependence). The interdependence groups are equivalent in gender, $\chi^{2}=845(2)$, $p=0.655$, and degree course, $\chi^{2}=5.432(4), p=0.246$.

On the other hand, in order to check if there are differences taking into account the type of interdependence in the attitudes towards teamwork, team potency and student's social skills, a multivariate analysis (MANOVA) is performed, which revealed significant multivariate main effects of the type of interdependence in the variables analyzed (Wilks $\lambda=0.818, F(14,818)=6187, p<0.001$, $\eta=0.096)$.

The univariate contrasts (Table 1) show the existence of a significant major effect of the type of interdependence in Academic and Social Attitudes, Team Potency (Confidence and Performance), and Self-assertion social skills.

Table 1. CACTE, CPA, and CHSEA's descriptives and univariate contrasts groups of interdependence.

\begin{tabular}{|c|c|c|c|c|c|c|c|c|c|c|c|}
\hline \multirow{3}{*}{$\begin{array}{l}\text { Dependent } \\
\text { Variable }\end{array}$} & \multicolumn{8}{|c|}{ Interdependence } & \multirow{2}{*}{\multicolumn{3}{|c|}{$\begin{array}{l}\text { Tests for Inter-Subject } \\
\text { Effects }\end{array}$}} \\
\hline & \multicolumn{2}{|c|}{ Total } & \multicolumn{2}{|c|}{ Low } & \multicolumn{2}{|c|}{ Medium } & \multicolumn{2}{|c|}{ High } & & & \\
\hline & $M$ & $S D$ & $M$ & $S T$ & $M$ & $S D$ & $M$ & $S D$ & $F$ & $p$ & $\eta^{2}$ \\
\hline $\begin{array}{l}\text { Academic } \\
\text { Attitudes }\end{array}$ & 23.71 & 4.37 & 19.75 & 4.77 & 23.06 & 4.26 & 25.15 & 3.66 & 19.881 & 0.000 & 087 \\
\hline $\begin{array}{c}\text { Social } \\
\text { Attitudes }\end{array}$ & 26.58 & 3.35 & $23.45^{a}$ & 4.05 & $25.92^{b}$ & 3.40 & $27.85^{c}$ & 2.42 & 36.468 & 0.000 & 149 \\
\hline Confidence & 31.77 & 5.11 & $29.02^{a}$ & 6.97 & $30.81^{a}$ & 4.86 & $33.21^{b}$ & 4.37 & 10.415 & 0.000 & 048 \\
\hline Performance & 33.10 & 4.25 & $31.36^{\mathrm{a}}$ & 5.85 & $32.38^{a}$ & 3.98 & $34.11^{b}$ & 3.83 & 8.813 & 0.000 & 041 \\
\hline $\begin{array}{l}\text { Imparting } \\
\text { Information }\end{array}$ & 20.39 & 2.83 & $20.36^{a}$ & 2.79 & $20.11^{a}$ & 2.90 & $20.65^{a}$ & 2.77 & 2.326 & 0.099 & 011 \\
\hline $\begin{array}{l}\text { Receiving } \\
\text { Information }\end{array}$ & 22.70 & 2.46 & $22.23^{a}$ & 2.69 & $22.38^{a}$ & 2.51 & $23.09^{a}$ & 2.31 & 2.644 & 0.072 & 013 \\
\hline Self-assertion & 20.62 & 2.79 & $20.27^{a, b}$ & 3.31 & $20.14^{a}$ & 2.84 & $21.11^{b}$ & 2.54 & 4.239 & 0.015 & 020 \\
\hline
\end{tabular}

In addition, multiple comparisons indicate that when students work in teams, (1) greater task interdependence, obtains higher scores $(p<0.05)$ in Teamwork Attitudes (Academic, $p<0.05$ and Social, 
$p<0.001)$; (2) the group with high task interdependence obtains higher scores $(p<0.05)$ in Team Potency (Confidence, $p \leq 0.004$ and Performance, $p \leq 0.027$ ) that those with low and medium interdependence group, with no differences $(p \leq 0.05)$ between the students of low and medium interdependence; (3) the high interdependence group achieves higher scores $(p<0.05)$ than those of medium interdependence in social skills Self-assertion, $p=0.020$, with no differences $(p \leq 0.05)$ between the students of low and high interdependence.

Once the existence of differences between the means of the three interdependence groups has been demonstrated by a discriminate analysis, we will analyze which variables (attitudes, potency or social team skills) explain these differences to a greater extent. The aim is to classify the participants and assign them to each of the interdependence groups according to the result of the linear combination of the set of independent variables. In our study, we have used predictive variables as the factors of the CACTE, the CPEA, and the CHSEA, and as dependent variables the different types of interdependence.

Table 2 shows the structure matrix that is created in the discriminant analysis. The analysis of the discriminant functions indicates that Function 1 is the one that presents the greatest power discrimination among the three groups of interdependence.

Table 2. Structure matrix.

\begin{tabular}{cccc}
\hline \multirow{4}{*}{ Structure matrix } \\
\hline \multirow{2}{*}{ CACTE } & Social Attitudes & Function 1 & Function 2 \\
\cline { 2 - 4 } & Academic Attitudes & $0.873^{*}$ & -0.158 \\
\hline \multirow{2}{*}{ CPEA } & Confidence & $0.631^{*}$ & 0.049 \\
\cline { 2 - 4 } & Performance & $0.566^{*}$ & 0.368 \\
\hline \multirow{2}{*}{ CHSEA } & Self-assertion & $0.455^{*}$ & 0.438 \\
\cline { 2 - 4 } & Imparting Information & 0.274 & $0.845^{*}$ \\
\cline { 2 - 4 } & Receiving Information & 0.121 & $0.578^{*}$ \\
\hline
\end{tabular}

Variables ordered by the size of the correlation with the discriminant function. ${ }^{*}$ Higher absolute correlation between each variable and the discriminant function.

Function 1 explains a much higher percentage of variance and shows a greater canonical correlation and distance between discriminated groups (Wilks' Lambda closer to 0 ). In addition, Chi-square analysis presents the highest level of significance. Function $1(\%$ variance $=95.8$, canonical correlation $=0.467$, Wilks $\left.\lambda: 0.733, \chi^{2}=107.119(14), p<0.001\right)$; Function $2(\%$ variance $=4.2$, canonical correlation $=0.110$, Wilks $\left.\lambda: 0.988, \chi^{2}=5.093(6), p=0.532\right)$. According to Function 1, the Social Attitudes factor (0.873) has the highest predictive capacity, followed by the Academic Attitudes (0.631) and the Confidence (0.566) and Performance (0.455) factors.

The centroids of the interdependence groups (low $=-1.134$, medium $=-0.270$, and high $=0.484$ ) allow us to interpret the relationship of each factor with the different groups. Showing that the students in the high interdependence group would be characterized by positive attitudes towards teamwork and greater confidence in the effectiveness and success of their own team. While students in groups of medium and, above all, low interdependence would be characterized by negative attitudes towards teamwork and little confidence in the effectiveness and success of their own team.

Finally, in Table 3, we observe that the canonical discriminant function obtained allows us to correctly classify $56.8 \%$ of students with low interdependence, $38.1 \%$ of those with medium interdependence, and $71.1 \%$ of those with high interdependence. 
Table 3. Results of the classification using the discriminant function.

\begin{tabular}{ccccccc}
\hline & \multicolumn{4}{c}{ Forecasted Group Membership } \\
\hline \multirow{2}{*}{ Interdependence } & \multicolumn{2}{c}{ Low } & \multicolumn{2}{c}{ Medium } & \multicolumn{2}{c}{ High } \\
\cline { 2 - 8 } & $\mathbf{N}$ & $\mathbf{\%}$ & $\mathbf{N}$ & $\%$ & $\mathbf{N}$ & $\%$ \\
\hline Low & 67 & 56.8 & 21 & 18.2 & 29 & 25.0 \\
\hline Medium & 96 & 26.7 & 137 & 38.1 & 127 & 35.2 \\
\hline High & 32 & 9.5 & 64 & 19.4 & 235 & 71.1 \\
\hline
\end{tabular}

Given the results obtained in the discriminant analysis which shows a high predictive capacity of both CACTE factors, an analysis of a receiver operating characteristic curve (ROC) was carried out with the intention of identifying the cut-off points of the CACTE total score, from which it is more likely that high interdependence exists when working in a team.

In the ROC analysis, the presence of High Interdependence was identified, the curve leaves an area of $0.873(p<0.001 ; 95 \%$ Confidence Interval; Min $=0.833$; Max $=0.914)$ under the nonparametric assumption.

Table 4 shows the cut-off point that simultaneously optimizes sensitivity and specificity and the cut-off points that optimize sensitivity and specificity.

Table 4. Sensibility, Specificity, and Youden's index for CACTE's scores.

\begin{tabular}{cccc}
\hline Cutting Point & Sensibility & Specificity & Youden's Index \\
\hline 40 & 0.959 & 0.568 & 0.527 \\
\hline 41 & 0.903 & 0.620 & 0.523 \\
\hline 43 & 0.868 & 0.677 & 0.545 \\
\hline $44^{*}$ & 0.827 & 0.750 & 0.577 \\
\hline 45 & 0.780 & 0.776 & 0.556 \\
\hline 46 & 0.720 & 0.813 & 0.532 \\
\hline 47 & 0.647 & 0.870 & 0.517 \\
\hline 48 & 0.560 & 0.906 & 0.467 \\
\hline
\end{tabular}

A score of 44 (equal or higher) simultaneously maximized CACTE's sensitivity (83\%) and specificity $(75 \%)$ for High Interdependency identification (Youden's Index $=0.577$ ). On the other hand, the score of 40 maximizes sensitivity (96\%) while maintaining specificity higher than expected by chance $(57 \%)$, and a cut-off point of 48 maximizes specificity $(91 \%)$ while retaining sensitivity (56\%) higher than expected by chance $(56 \%)$.

\section{Discussion}

In this study, the objective was to determine the extent to which university students are interdependent when carrying out tasks or teamwork. At the same time, the similarities and differences in measures of attitudes, potency, and social skills of the team were analyzed, depending on the task interdependence. This was done in order to identify which of these variables have greater power of discrimination or better quantify the differences between the different levels of task interdependence that the students use when they carry out the tasks in university contexts.

In the first place, the percentages found in the groups of low, medium, and high interdependence show that those university student-participants in this study, who carry out the tasks in a team with high interdependence are a minority. Without task interdependence, there can be no teamwork. The interaction around a team task generates different degrees of interdependence among its 
members [24]. Depending on the cooperation required to perform the task perceived by the team members, they will modulate their levels of interdependence [42]. This would indicate that a high percentage of teamwork does not require a high degree of task interdependence, e.g., it can be done with a low degree of involvement, interaction, and cooperation in the tasks between them. This would partly explain why a majority of students are not used to working cooperatively, underlining the importance of preparing students to cooperate when working together [43].

In relation to gender, our results show that gender does not seem to have any effect on the type of interdependence of tasks. The PISA report evaluating teamwork [3] shows that while boys are more efficient at completing a task and finding the necessary information, girls are more cooperative, more interested in the opinions of others, and want others to succeed. While the report focuses on 15-year-olds, we believe it offers a possible explanation for the fact that the girls in the study have greater confidence in the effectiveness and success of their own team as well as greater information-receiving skills.

On the other hand, the results obtained in the average comparisons showed that in general, students who maintain a high interdependence when working in a team are subjects with more positive attitudes towards teamwork show greater team potency and more social skills in receiving information and self-assertion. Just as group coordination and cohesion is very important when task interdependence is high [24], our results would support that interdependence favors confidence and cohesion among team members [27], plays a moderating role in helping behavior, confidence, communication, conflict, or flexibility [26], and increases motivation for teamwork [30].

Likewise, the discriminant analysis confirms that a high interdependence would be characterized by high scores in attitudes and team potency. Given the relationships of positive attitudes towards teamwork, team potency, satisfaction, and motivation to work as a team [41], our results would confirm that team members who are satisfied with their team $[16,45,46]$ and motivated to work as a team [30] would have a high team interdependence. Although team potency is one of the most relevant motivational variables related to group effectiveness that improves the attitude of team members to successfully carry out a task [40], the variables that can best discriminate the type of interdependence are social and academic attitudes towards teamwork. According to the guidelines for the valuation of the area under the curve (AUC) [47], the CACTE questionnaire would allow an excellent level of discrimination of high interdependence.

This study presents limitations that need to be considered. First, more objective measures of interdependence would be desirable. Second, although we obtained group data from six Spanish universities, the generalization of our findings needs to be considered given the diversity of degrees with different conditions that may or may not have strengthened group processes. In addition, we believe it would be of interest to analyze how the social attitudes, team potency, and team skills mediates on task interdependence through an experimental design that would allow us to establish causal relationships.

Despite these limitations, our results confirm the importance and the need to pay attention to interdependence when teachers design tasks or teamwork, as well as to the control of emerging variables resulting from the experiences and previous interactions of team members, such as the team potency or student's attitudes towards teamwork.

\section{Conclusions}

Our results mainly show the importance of teamwork attitudes as an indicator of task interdependence. If attitudes are not taken into account, there may be unsatisfactory work experiences that discourage students from working in teams or working in conditions of minimal interdependence. These negative experiences can create negative attitudes towards teamwork, affecting their future teamwork experiences. On the contrary, a positive learning experience can improve attitudes toward teamwork, efficiency, and cooperation with classmates, which would improve the willingness to work in a team [48]. 
We believe that one way to ensure high task interdependencies is through the use of cooperative learning techniques or strategies [49-51]. However, in the university context, it is necessary for students to work much of the time autonomously and these type of learning techniques requires constant supervision of the team. Therefore, when it is intended that students acquire autonomously skills for teamwork and cooperation as a team, it is crucial to design tasks that requires a high degree of interdependence. Working autonomously will only have a positive effect on team performance under highly interdependent conditions [52].

Finally, it is important to point out that the participatory and interdisciplinary structure of cooperative learning facilitates learning that encompasses all the elements that make up an education for sustainability. Sustainable Education aims to help people develop moral values of justice and solidarity, enabling them to make decisions about environmental and development issues globally. Sustainable Education requires participatory teaching methods that replace competitiveness with cooperation, and lead to the understanding that the success that leads to the failure of others is not sustainable. In this sense, maximum interdependence in cooperative learning situations fosters the student's values and competencies, such as individual responsibility, the ability to cooperate and interact socially, logical and critical reasoning, and problem-solving skills. All of these values and competencies have been set by UNESCO [53] as priority goals in the field of Education, as they are key to most organizational systems, and essential for working together towards a sustainable future.

Author Contributions: Conceptualization, B.L.D.B., S.M.L., M.-I.P.-D.-R. and I.R-G.; Methodology, B.L.D.B. and S.M.L.; Formal analysis, B.L.D.B. and S.M.L.; Data curation, B.L.D.B. and S.M.L.; Writing-original draft preparation, B.L.D.B., S.M.L., M.-I.P.-D.-R. and I.R.-G.; Writing-review and editing, B.L.D.B., S.M.L., M.-I.P.-D.-R. and I.R.-G. All authors have read and agreed to the published version of the manuscript.

Funding: This research received no external funding.

Acknowledgments: In this section you can acknowledge any support given which is not covered by the author contribution or funding sections. This may include administrative and technical support, or donations in kind (e.g., materials used for experiments).

Conflicts of Interest: The authors declare no conflict of interest.

\section{References}

1. Atxurra, C.; Villardón-Gallego, L.; Calvete, E. Design and Validation of the Cooperative Learning Application Scale (CLAS). Rev. Psicodidact. 2015, 20, 339-357. [CrossRef]

2. Rayón, L.; De las Heras, A.M.; Muñoz, Y. Creation and management of knowledge in higher education: Autonomy, self-regulation and collaboration in learning. RIES 2011, 2, 103-122.

3. PISA 2015 Assessment and Analytical Framework. Paris; OECD Publishing: Paris, France, 2017. [CrossRef]

4. León, B.; Felipe, E.; Iglesias, D.; Marugán, M. Factors in cooperative learning efficiency. Exp. EHEA RIE 2014, 32, 411-424.

5. Gámez-Montalvo, M.J.; Torres-Martín, C. Group techniques as a methodological strategy in acquiring teamwork abilities by college students. J. Educ. Teach. Train. 2013, 4, 14-25.

6. León, B.; Latas, C. The formation in techniques of cooperative learning of the universityprofessor in the context of the European convergence. Rev. Psicodidact. 2007, 12, 259-278.

7. Guzzo, R.A.; Dickson, M.W. Teams in organizations. Recent research on performance effectiveness. Annu. Rev. Psychol. 1996, 47, 307-338. [CrossRef]

8. Kelley, T.; Littman, J. The Ten Faces of Innovation; Doubleday: New York, NY, USA, 2005.

9. Monereo, C.; Castelló, M.; Martínez-Fernández, J.R. Prediction of Success in Teamwork of Secondary Students. Rev. Psicodidact. 2013, 18, 235-255. [CrossRef]

10. Campion, M.A.; Medsker, G.J.; Higgs, A.C. Relations between work group characteristics and effectiveness: Implications for designing effective work groups. Pers. Psychol. 1993, 46, 823-847. [CrossRef]

11. Thompson, J.D. Organizations in Action; McGraw-Hill: New York, NY, USA, 1967.

12. Johnson, D.; Johnson, R.; Smith, K. Active Learning; Edina, M.N., Ed.; Interaction Book Co.: Minneapolis, MN, USA, 2006. 
13. Skilton, P.F.; Forsyth, D.; White, O.J. Interdependence and integration learning in student project teams: Do team project assignments achieve what we want them to? J. Mark. Educ. 2008, 30, 57-65. [CrossRef]

14. Johnson, D.W.; Johnson, R.T. Cooperative learning and social interdependence theory. In Theory and Research on Small Groups; Springer: Boston, MA, USA, 2002; pp. 9-35.

15. Ortiz, A.E.; Johnson, D.W.; Johnson, R.T. The effect of positive goal and resource interdependence on individual performance. J. Soc. Psychol. 1996, 136, 243-249. [CrossRef]

16. Van der Vegt, G.S.; Emans, B.J.; Van der Vliert, E. Patterns of interdependence in work teams: A two-level investigation of the relations with job and team satisfaction. Pers. Psychol. 2001, 54, 51-69. [CrossRef]

17. De Dreu, C.K. Cooperative outcome interdependence, task reflexivity, and team effectiveness: A motivated information processing perspective. J. Appl. Psychol. 2007, 92, 628-638. [CrossRef] [PubMed]

18. Saavedra, R.; Earley, P.C.; Van Dyne, L. Complex interdependence in task-performing groups. J. Appl. Psychol. 1993, 78, 61-72. [CrossRef]

19. León, B.; Felipe, E.; Mendo, S.; Iglesias, D. Habilidades sociales en equipos de aprendizaje cooperativo en el contexto universitario. Behav. Psychol. 2015, 23, 191-214.

20. Aritzeta, A.; Ayestarán, S. The Utility of Work Teams in increasing participation, self-management, interdependence, satisfaction and the integration of co-operative and competitive behaviours CIRIEC-España. CIRIEC-ESPAÑ 2002, 40, 195-212.

21. Navarro, J.; Quijano, S.D.; Berger, R.; Meneses, R. Workgroups in organizations: A basic tool to manage increasing uncertainty and ambiguity. Pap. Psicol. 2011, 32, 17-28.

22. O'Brien, M. Who's Got the Ball? Jossey-Bass: San Francisco, CA, USA, 1995.

23. Taggar, S.; Haines, V.Y., III. I need you, you need me: A model of initiated task interdependence. J. Manag. Psychol. 2006, 21, 211-230. [CrossRef]

24. Alonso, R.E. Modelo de la Contingencia y Eficacia Organizacional: Una Evaluación del Impacto de Programas de Empleo. Ph.D. Thesis, Universidad de Almería, Servicio de Publicaciones, Almería, Spain, 23 April 2004.

25. Mena, B.; Barrasa, Á.; Gil, F. Analysis of the influence of interdependence and group potency on work teams' performance in health contexts. Rev. Psicol. Soc. 2012, 27, 111-122. [CrossRef]

26. Rico, R.; Alcover, C.M.; Tabernero, C. Work Team Effectiveness, a Review of Research over the last Decade (1999-2009). Rev. Psicol. Trab. Organ. 2010, 26, 47-71.

27. Gil, F.; Rico, R.; Sánchez-Manzanares, M. The effectiveness of work teams. Pap. Psicol. 2008, $29,25-31$.

28. Saravanabawan, A.; Long, L. How Task interdependence Moderate the Effect of Team Member Collectivism on Team Creativity: An Empirical Study in Sri Lankan Context. Int. J. Curr. Adv. Res. 2014, 2, 144-156.

29. Somech, A.; Desivilya, H.S.; Lidogoster, H. Team conflict management and team effectiveness: The effects of task interdependence and team identification. J. Organ. Behav. 2009, 30, 359-378. [CrossRef]

30. Hertel, G.; Konradt, U.; Orlikowski, B. Managing distance by interdependence: Goal setting, task interdependence, and team-based rewards in virtual teams. Eur. J. Work Organ. Psychol. 2004, 13, 1-28. [CrossRef]

31. León, B. Mediatory elements in the efficiency of cooperative learning: Previ-ous training in social skills and group dynamics. An. Psicol. 2006, 22, 105-112.

32. Tajfel, H. Interindividual behaviour and intergroup behaviour. Differ. Between Soc. Groups Stud. Soc. Psychol. Intergroup Relat. 1978, 1978, 27-60.

33. Postmes, T.; Spears, R.; Lea, M. Social Identity, Group Norms, and" Deindividuation": Lessons from Computer-Mediated Communication for Social Influence in the Group; Ellemers, N., Spears, R., Doosje, B., Eds.; Social Identity: Context, Commitment, Content; Blackwell: Oxford, UK, 1999.

34. Woolley, A.W.; Aggarwal, I.; Malone, T.W. Collective Intelligence in Teams and Organizations; Malone, T.W., Bernstein, M.S., Eds.; The Handbook of Collective Intelligence; MIT Press: Cambridge, MA, USA, 2015.

35. Van den Bossche, P.; Gijselaers, W.H.; Segers, M.; Kirschner, P.A. Social and cognitive factors driving teamwork in collaborative learning environments: Team learning beliefs and behaviors. Small Group Res. 2006, 37, 490-521. [CrossRef]

36. García, R.; Traver, J.A.; Candela, I. Aprendizaje Cooperativo. Fundamentos, Característicasy Técnicas; CCS-ICCE: Madrid, Spain, 2001.

37. Gundlach, M.; Zivnuska, S.; Stoner, J. Understanding the relationship between individualism-collectivism and team performance through an integration of social identity theory and the social relations model. Hum. Relat. 2006, 59, 1603-1632. [CrossRef] 
38. De Jong, S.B.; Van der Vegt, G.S.; Molleman, E. The relationships among asymmetry in task dependence, perceived helping behavior, and trust. J. Appl. Psychol. 2007, 92, 1625-1637. [CrossRef]

39. Mathieu, J.E.; Schulze, W. The influence of team knowledge and formal plans on episodic team process-performance relationships. Acad. Manag. J. 2006, 49, 605-619. [CrossRef]

40. León, B.; Mendo, S.; Felipe, E.; Polo, M.I.; Fajardo, F. Team Potency and Cooperative Learning in the University Setting. Rev. Psicodidact. 2017, 22, 9-15. [CrossRef]

41. Gardner, B.S.; Korth, S.J. A framework for learning to work in teams. JEB. 1998, 74, 28-33. [CrossRef]

42. Castelló, T. Procesos de cooperación en el aula. In Cooperar en la escuela. La Responsabilidad de Educar Para la Democracia; Graó: Barcelona, Spain, 1998; pp. 51-71.

43. Mendo, S.; Polo, M.I.; Iglesias, D.; Felipe, E.; León, B. Construction and Validation of a Measurement Instrument for Attitudes Towards Teamwork. Front. Psychol. 2017, 8, 1-10. [CrossRef]

44. Rico, R.; Sánchez-Manzanares, M.; Gil, F.; Alcover, C.M.; Tabernero, C. Procesos de coordinación en equipos de trabajo. Pap. Psicol. 2011, 32, 59-68.

45. Buchs, C.; Butera, F. Cooperative learning and social skills development. In Collaborative Learning: Developments in Research and Practice; Gillies, R., Ed.; Nova Science; EEUU: New York, NY, USA, 2015; pp. 201-217.

46. Shaw, J.D.; Duffy, M.K.; Stark, E.M. Interdependence and preference for group work: Main and congruence effects on the satisfaction and performance of group members. J. Manag. 2000, 26, 259-279. [CrossRef]

47. Hosmer, D.W.; Lemeshow, S. Applied Logistic Regression; Wiley-Interscience: New York, NY, USA, 2000.

48. Ekimova, V.; Kokurin, A. Students' Attitudes towards different team building methods. Procedia Soc. Behav. Sci. 2015, 186, 847-855. [CrossRef]

49. Kagan, S. Cooperative Learning; Resources for Teachers: San Clemente, CA, USA, 1994.

50. Pujolás, P. Introducción al Aprendizaje Cooperativo; Universidad de Vich: Barcelona, Spain, 2009.

51. Slavin, R.E.; Johnson, R.T. Aprendizaje Cooperativo: Teoría, Investigación y Práctica; Aique: Buenos Aires, Argentina, 1999.

52. Langfred, C.W. Autonomy and performance in teams: The multilevel moderating effect of task interdependence. J. Manag. 2005, 31, 513-529. [CrossRef]

53. UNESCO. Roadmap for Implementing the Global Action Programme on Education for Sustainable Development; UNESCO: Paris, France, 2014. Available online: http://unesdoc.unesco.org/images/0023/002305/230514e.pdf (accessed on 10 October 2019). 